\title{
Responses of Saturated Sand Surrounding A Bucket Foundations Under Horizontal Vibration Loading
}

\author{
Xiaobing $\mathrm{Lu}^{*}, 1$, Xuhui Zhang ${ }^{1}$ and Zhongmin $\mathrm{Shi}^{2}$ \\ ${ }^{1}$ Institute of Mechanics, Chinese Academy of Sciences, Beijing, 100190, China \\ ${ }^{2}$ Research Center of China Ocean Oil Co., Beijing, 100027, China
}

\begin{abstract}
In this paper we investigated the responses of saturated sand under horizontal vibration loading induced by a bucket foundation. It is shown that the saturated sand liquefies gradually since the vibration loading is applied on. The maximum displacement on the surface of sand layer occurs near the loading end and in this zone the sand is compressed and moves upwards. The liquefaction zone is developed from the upper part near the loading side and stopped gradually.
\end{abstract}

Keywords: Liquefaction, saturated sand, vibration loading, bucket foundation.

\section{INTRODUCTION}

A suction bucket foundation is a closed-top steel tube that is lowered to the seafloor, allowed to penetrate the bottom sediments under its own weight first, and then pushed to full depth with suction force produced by pumping water out of the interior. In recent years, suction bucket foundations have been used increasingly for gravity platform, jackets, jack-ups etc. [1, 2]. They also have the potential of being used for several other purposes, such as offshore wind turbines, subsea systems and seabed protection structures [3-6]. The first advantage of suction bucket foundations are the convenient method of installation and repeatedly use. For an example, a suction bucket foundation with a diameter of $9 \mathrm{~m}$ and a height of $10 \mathrm{~m}$ can be installed in 1 3 hours, by using only a pump. The second advantage is that it may mobilize a significant amount of passive suction during uplift under some conditions, although the mobilisation of suction depends mainly on the load rate and recommendations are actually to not rely on the suction for design [7]. Despite some studies about the installation and bearing capacity have been studied, the detail responses of the suction bucket foundations under dynamic loads have remained unknown [8-10]. The dynamic load condition is significant when suction buckets are used as the foundation of an offshore structure. Wave load, ice-induced or wind-induced load cause the foundation to be subjected to cyclic loads $[11,12]$.

The liquefaction caused by earthquake had been investigated for many years [13-16]. With the development of ocean oil and gas engineering, many platforms are installed in deeper and deeper ocean zone. The instability of bucket foundations and the liquefaction of soil layer surrounding the bucket under dynamic loading, such as wave loading or earthquake, is a focus in recent. If the sand foundation has liquefied around a bucket foundation, the sand may become

*Address correspondence to this author at the Institute of Mechanics, Chinese Academy of Sciences, Beijing, 100190, China; Tel: 13641286387; E-mail: xblu@imech.ac.cn loose and the strength degrades to a very small value, then it is easy to be scoured and the sand around the bucket may be push upwards. As a result, the gap between the bucket foundation and the soil layer is bigger and bigger. Thus the bucket loses stability without the back of soil layer. In this paper, we investigated the responses of bucket foundations under horizontal dynamic loadings (Fig. 1).

\section{THE BASIC EQUATIONS}

\section{The Constitutive Relation}

The constitutive relation of a two-linear model is adopted [17]. This model is consisted of loading part and unloading part.

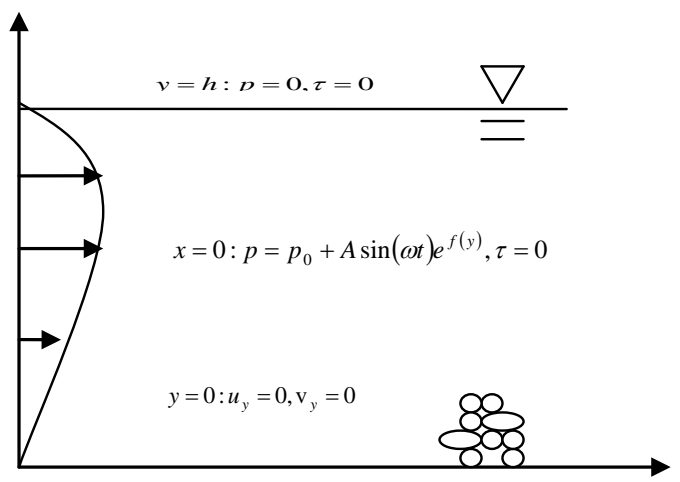

Fig. (1). The sketch of the problem.

The expression of the constitutive relation is shown as follows:

$$
\left\{\begin{array}{c}
\sigma_{e x}-\sigma_{e x 0}=\frac{E_{L}}{(1-2 v)(1+v)} \cdot\left((1-v) \varepsilon_{x}+v \varepsilon_{y}\right) \\
\sigma_{e x}-\sigma_{e x 0}=\frac{E_{L}}{(1-2 v)(1+v)} \cdot\left((1-v) \varepsilon_{x}+v \varepsilon_{y}\right) \\
\tau=\frac{E_{1}}{2(1+v)} \gamma_{x y}
\end{array}\right.
$$


In which $L=1,2$ denotes the conditions of loading and unloading, respectively. Assuming that

$$
E_{L}=E_{0 L} \cdot\left(\frac{\left(\sigma_{e x} \cdot \sigma_{e y}-\tau^{2}\right)^{0.5}}{\left(\sigma_{e x 0} \cdot \sigma_{e y 0}-\tau_{0}{ }^{2}\right)^{0.5}}+0.001\right)
$$

in which $E_{L}$ is the modulus of the sand skeleton which has different data under loading and unloading conditions. $E_{0 L}$ denotes the initial loading ( $L=1$ ) and unloading ( $L=2$ ) modulus of the soil skeleton, $\boldsymbol{v}$ is the poission's ratio. The criterion for judging the loading and unloading conditions is: It is loading when $\gamma_{\text {oct } 2}>\gamma_{\text {oct } 1}$; otherwise it is unloading $\gamma_{o c t 2}, \gamma_{o c t 1}$ are the octahedron strain before and after a given time.

\section{The Equilibrium Equations and the Initial and Boundary Conditions}

The governing equations of the saturated sand were first established for dynamic phenomenon by Biot (1956) [13] and some analytical results were given by Biot [14] afterwards. At later, governing equations based on mixture theory were proposed $[15,16]$, but the rederivation of the equations was achieved with no substantial or rational change from Biot's equations. In this paper we adopt the following controlling equations [17]:

$$
\left\{\begin{array}{c}
\frac{\partial n}{\partial t}+\frac{\partial n v_{x}}{\partial x}+\frac{\partial n v_{y}}{\partial y}=0 \\
\frac{\partial(1-n)}{\partial t}+\frac{\partial(1-n) u_{x}}{\partial x}+\frac{\partial(1-n) u_{y}}{\partial y}=0 \\
\rho_{w} \cdot n\left(\frac{\partial v_{x}}{\partial t}+v_{x} \frac{\partial v_{x}}{\partial x}+v_{y} \frac{\partial v_{x}}{\partial y}\right)+n \frac{\partial p}{\partial x}=-H_{1} \\
n \rho_{w} \cdot\left(\frac{\partial v_{x}}{\partial t}+v_{x} \frac{\partial v_{x}}{\partial x}+v_{y} \frac{\partial v_{x}}{\partial y}\right)+n \frac{\partial p}{\partial y}=-H_{1}+n \rho_{w} g \\
(1-n) \cdot \rho_{s} \cdot\left(\frac{\partial u_{x}}{\partial t}+u_{x} \frac{\partial u_{x}}{\partial x}+u_{y} \frac{\partial u_{x}}{\partial y}\right)+(1-n) \cdot \frac{\partial p}{\partial x}+\frac{\partial \sigma_{e}}{\partial x}+\frac{\partial \tau}{\partial y}=H_{2}+(1-n) \rho_{s} g \\
(1-n) \cdot \rho_{s} \cdot\left(\frac{\partial u_{x}}{\partial t}+u_{x} \frac{\partial u_{x}}{\partial x}+u_{y} \frac{\partial u_{x}}{\partial y}\right)+(1-n) \cdot \frac{\partial p}{\partial y}+\frac{\partial \sigma_{e}}{\partial y}+\frac{\partial \tau}{\partial x}=H_{2}+(1-n) \rho_{s} g
\end{array}\right.
$$

in which $\mathrm{n}$ is the porosity, $v_{x}, v_{y}$ are respectively the velocities of water in $x$ and $y$ directions, $u_{x}, u_{y}$ are respectively the velocities of the grains in $x$ and $y$ directions, $\rho_{w}$ is the density of water, $\rho_{s}$ is the density of grains, $\mathrm{p}$ is the pore pressure, $\sigma_{e x}, \sigma_{e y}$ are the effective stresses in $x$ and $y$ directions, respectively, $\tau$ is the shear stress, $\beta$ is the compressibilily coefficient of water, $g$ is the gravity acceleration, $H_{1,2}$ are the drag between water and grains in $x$ and $y$ directions and are assumed as

$$
\begin{aligned}
& H_{1}=n^{2}\left(\mathrm{v}_{x}-\mathrm{u}_{x}\right) / K \\
& H_{2}=n^{2}\left(\mathrm{v}_{y}-\mathrm{u}_{y}\right) / K
\end{aligned}
$$

in which $K$ is the drag coefficient between water and grains and $K=k / \mu, \mu$ is the viscosity of water, $\mathrm{k}$ is the permeability.

The geometric relations connecting the velocity of grains $v_{s}$ and the strain ratio $\dot{\varepsilon}$, and the relation of the drag coefficient $K$ and the porosity $n$ are adopted as follows:

$$
\begin{aligned}
& \dot{\varepsilon}_{x}=-\frac{\partial u_{x}}{\partial x}, \dot{\varepsilon}_{y}=-\frac{\partial u_{y}}{\partial x}, \dot{\gamma}=-\left(\frac{\partial u_{x}}{\partial y}+\frac{\partial u_{y}}{\partial x}\right) \\
& K=\left(\frac{n}{n_{0}}\right)^{5}\left(\frac{1-n_{0}}{1-n}\right)^{2} K_{0}
\end{aligned}
$$

in which $K_{0}$ is the initial drag coefficient when the initial porosity of sand is $n_{0}$.

The initial conditions are as follows:

$t=0$ :

$$
\left\{\begin{array}{c}
p=\rho_{w} g \cdot(h-y) \\
\sigma_{e y 0}=\left(1-n_{0}\right)\left(\rho_{s}-\rho_{w}\right) g \cdot(h-y) \\
\sigma_{e x 0}=K_{0} \cdot \sigma_{e y 0} \\
u_{w x}=u_{w y}=u_{s x}=u_{s y}=0, n_{0}=0.4
\end{array}\right.
$$

in which $f_{1}(y)$ is the distribution function of the initial porosity, $k$ is the lateral pressure coefficient.

The boundary conditions are as follows:

At the upper side $y=h: p=0, \tau=0, \sigma_{e}=0$

At the bottom $y=0: u_{w y}=u_{s y}=u_{s x}=0$

At the left side

$$
\begin{aligned}
& x=0: \sigma_{e x}+p=\sigma_{e x 0}+p_{0}+A \sin (\omega t) \cdot e^{f(y)}, \tau=0, \\
& \frac{\partial p}{\partial x}=0
\end{aligned}
$$

At the right side: there is no reflection.

in which $A, \omega$ are the amplitude and the frequency of loading, respectively. $H$ is the thickness of sand.

The following difference scheme is adopted to obtain the numerical solution:

$$
\frac{\partial f}{\partial t}=\frac{f_{i}^{j}-f_{i}^{j-1}}{\Delta t}, \frac{\partial f}{\partial x}=\frac{f_{i}^{j}-f_{i-1}^{j}}{\Delta x}
$$

The dimensionless form of eq. (2) may be obtained as follows: 


$$
\left\{\begin{array}{c}
\frac{\partial n}{\partial \bar{t}}+\frac{\partial n \bar{v}_{x}}{\partial \bar{x}}+\frac{\partial n \bar{v}_{y}}{\partial \bar{y}}=0 \\
\frac{\partial(1-n)}{\partial \bar{t}}+\frac{\partial(1-n) \bar{u}_{x}}{\partial \bar{x}}+\frac{\partial(1-n) \bar{u}_{y}}{\partial \bar{y}}=0 \\
\bar{\rho}_{w} \cdot n\left(\frac{\partial \bar{v}_{x}}{\bar{\partial} t}+\bar{v}_{x} \frac{\partial \bar{v}_{x}}{\partial \bar{x}}+\bar{v}_{y} \frac{\partial \bar{v}_{x}}{\partial \bar{y}}\right)+n \frac{\partial \bar{p}}{\partial \bar{x}}=-\bar{H}_{1} \\
n \bar{\rho}_{w} \cdot\left(\frac{\partial \bar{v}_{x}}{\partial \bar{t}}+\bar{v}_{x} \frac{\partial \bar{v}_{x}}{\partial \bar{x}}+\bar{v}_{y} \frac{\partial \bar{v}_{x}}{\partial \bar{y}}\right)+n \frac{\partial \bar{p}}{\partial \bar{y}}=-\bar{H}_{1}+n \bar{\rho}_{w} \bar{g} \\
(1-n)\left(\frac{\partial \bar{u}_{x}}{\partial \bar{t}}+\bar{u}_{x} \frac{\partial \bar{u}_{x}}{\partial \bar{x}}+\bar{u}_{y} \frac{\partial \bar{u}_{x}}{\partial \bar{y}}\right)+(1-n) \frac{\partial \bar{p}}{\partial \bar{x}}+\frac{\partial \overline{\sigma_{e}}}{\partial \bar{x}}+\frac{\partial \bar{\tau}}{\partial \bar{y}}=\bar{H}_{2}+(1-n) \bar{g} \\
(1-n) \bar{\rho}_{s}\left(\frac{\partial \bar{u}_{x}}{\bar{\partial} t}+\bar{u}_{x} \frac{\partial \bar{u}_{x}}{\partial \bar{x}}+\bar{u}_{y} \frac{\partial \bar{u}_{x}}{\partial \bar{y}}\right)+(1-n) \frac{\partial \bar{p}}{\partial \bar{y}}+\frac{\partial \bar{\sigma}_{e}}{\partial \bar{y}}+\frac{\partial \bar{\tau}}{\partial \bar{x}}=\bar{H}_{2}+(1-n) \bar{\rho}_{s} \bar{g} \\
H_{1}=n^{2}\left(\mathrm{v}_{x}-\mathrm{u}_{x}\right) / K \\
H_{2}=n^{2}\left(\mathrm{v}_{y}-\mathrm{u}_{y}\right) / K
\end{array}\right.
$$

The dimensionless form of the constitutive relation and the initial and boundary conditions are obtained as follows:

The dimensionless initial conditions are as follows:

$$
\begin{aligned}
& t=0, \\
& n=f_{1}(y), \bar{p}=\bar{\rho}_{w} \bar{g} \cdot \bar{y}, \bar{\sigma}_{e y} \\
& =\left(1-n_{0}\right)\left(\bar{\rho}_{s}-\bar{\rho}_{w}\right) \bar{g} \cdot \bar{y}, \bar{v}_{w}=\bar{v}_{s}=0, \\
& \bar{\sigma}_{e x}=\left(1-n_{0}\right)\left(\bar{\rho}_{s}-\bar{\rho}_{w}\right) \bar{g} \cdot \bar{y} \cdot \bar{k}
\end{aligned}
$$

The dimensionless boundary conditions are as follows

$$
\left\{\begin{array}{c}
\bar{x}=0, \bar{p}=\bar{A}_{1} \sin (2 \bar{\pi} \overline{f t}) \\
\bar{y}=\bar{L}, \bar{\sigma}_{e x}=\bar{\sigma}_{e y}=\bar{p}=0 \\
\bar{y}=0 \cdot \frac{\partial \bar{p}}{\partial \bar{y}}=0, \bar{v}_{y}=\bar{u}_{x}=\bar{u}_{y}=0
\end{array}\right.
$$

\section{THE DEVELOPMENT OF LIQUEFACTION ZONE}

The values of the parameters adopted in computing are as follows: the thickness of the sand layer is $1.2 \mathrm{~m}$, the density of the sand is $\rho_{s}=2400 \mathrm{~kg} / \mathrm{m}^{3}$, the porosity is $n=0.4$, the possion's ratio is $v=0.3$, the density of water $\rho_{w}=1000 \mathrm{~kg} / \mathrm{m}^{3}$, the dimensionless modulus $E / \rho_{w} \operatorname{ghtan} \varphi$ equal $1 \times 10^{2}, 2 \times 10^{2}, 3 \times 10^{2}$, respectively, the dimensionless amplitudes of loading $A / \rho_{w}$ gh are $0.01,0.05,0.1$ respectively, the dimensionless frequencies of loading $f \rho_{w} / \mathrm{k}$ are $8.3 \times 10^{-4}, 1.25 \times 10^{-3}$ and $1.7 \times 10^{-3}$, respectively.

Fig. (2) shows the development of liquefaction zone is faster at the upper part than at. It is shown that under the vibration loading from the left side, the liquefaction zone develops first near the loading side, and then develops from left to right gradually. The smaller the modulus is, the faster the development of the liquefaction zone is. The development of liquefaction zone is faster at the upper side than at the lower part.
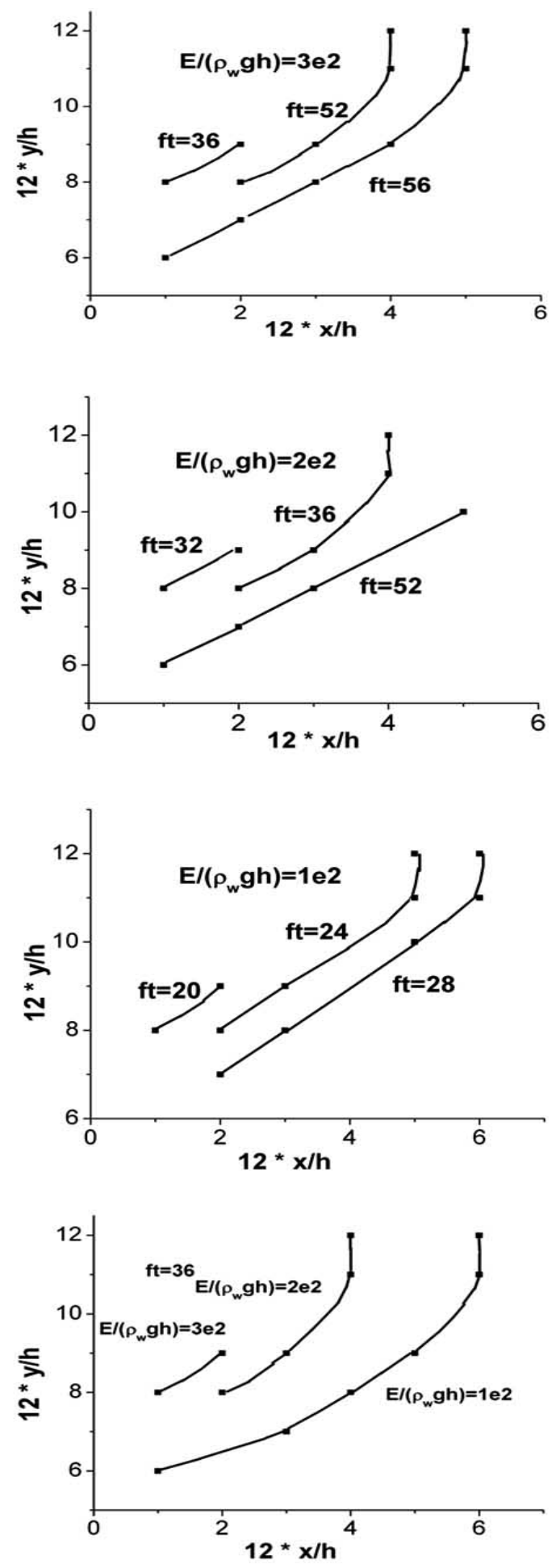

Fig. (2). The development of liquefaction zone with modulus.

Fig. (3) shows the development of liquefaction zone with time under different loading amplitudes. It is shown that the liquefaction development becomes fast and the liquefaction zone becomes large with the increase of the loading amplitude. Nevertheless, the expansion velocity of the liquefaction zone becomes smaller and smaller. There is a limited liquefaction zone under given conditions. 

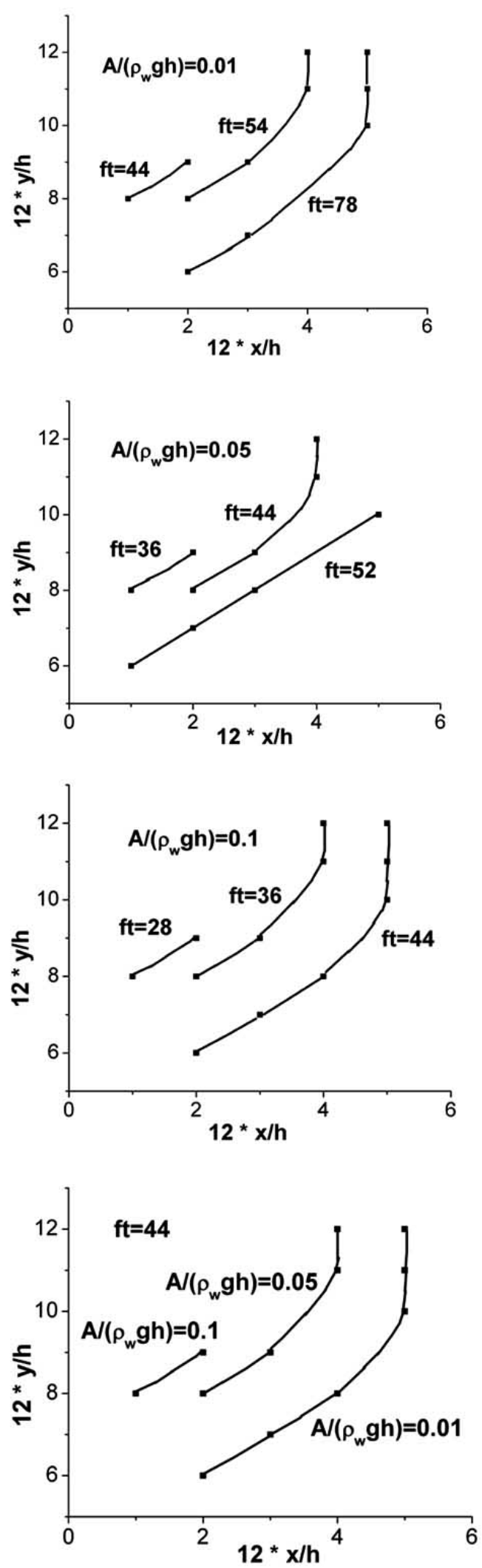

Fig. (3). The development of liquefaction zone with loading amplitude.

Fig. (4) shows the results of development of liquefaction zone under different frequencies. It is shown that with the increase of the frequency, the development of liquefaction zone becomes fast. But the developing velocity becaomes smaller and smaller.
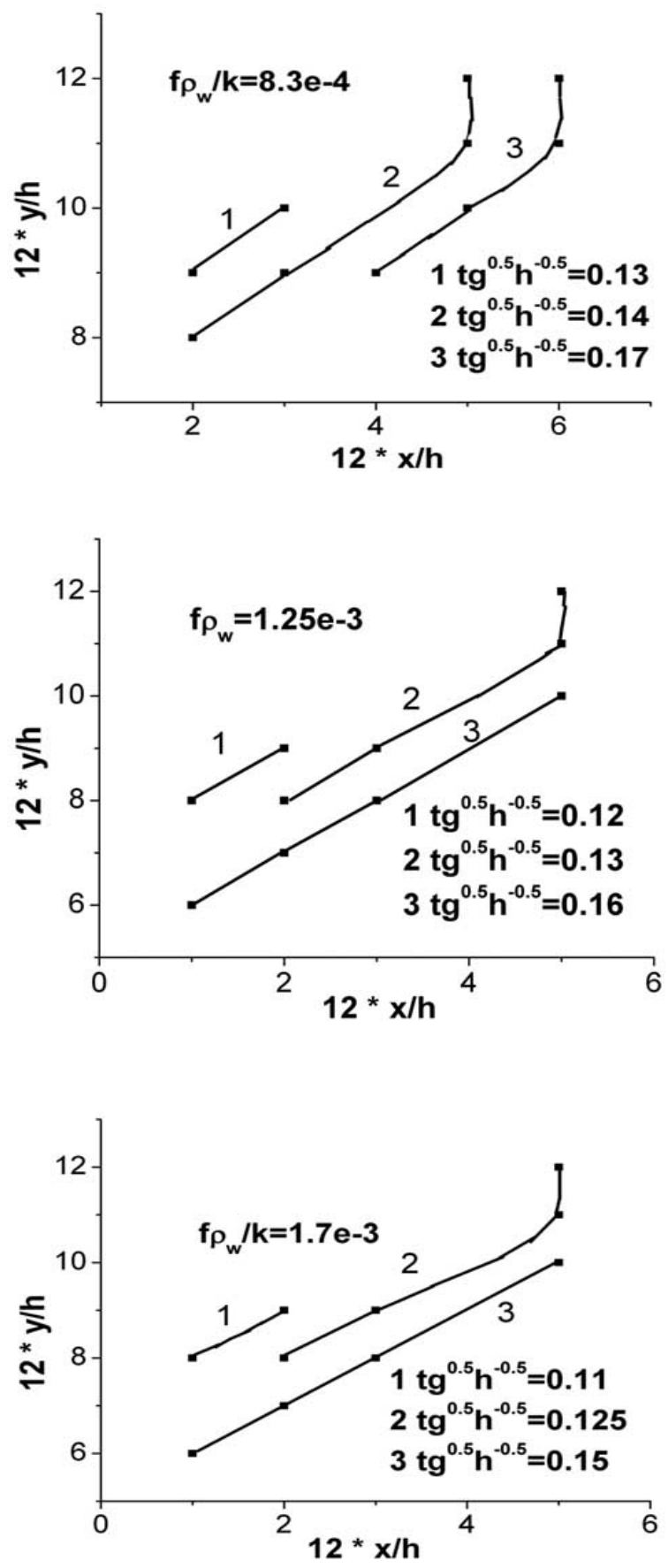

Fig. (4). The development of liquefaction zone with load frequency.

\section{THE DEVELOPMENT OF DISPLACEMENT ON THE SAND LAYER SURFACE}

Fig. (5) shows the vertical deformation of the sand layer under different modulus of sand layer. It is shown that with the application of vibration loading on the left side of the saturated sand, there is an up-heave on the upper side. The sand surface near the loading side becomes up-heave first and then develops to faraway, the deformation degrades 
from the loading side to far away. The deformation decreases with the decrease of the modulus.
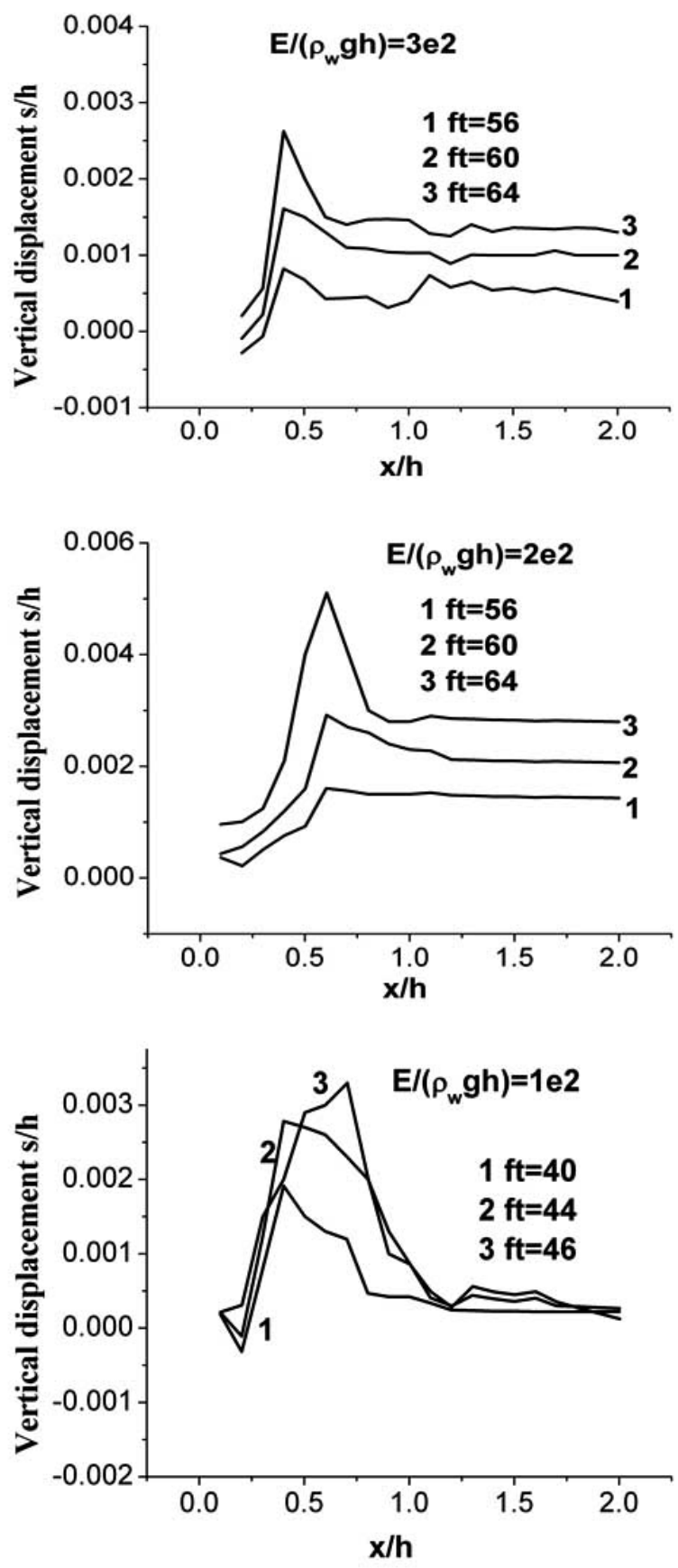

Fig. (5). The displacement on the upper side of the sand layer.

Fig. (6) shows the results of the surface deformation of the sand layer under different loading amplitudes. It is shown that the development of the displacement becomes large with the increase of the loading amplitude.The sand is pushed away from the loading end.
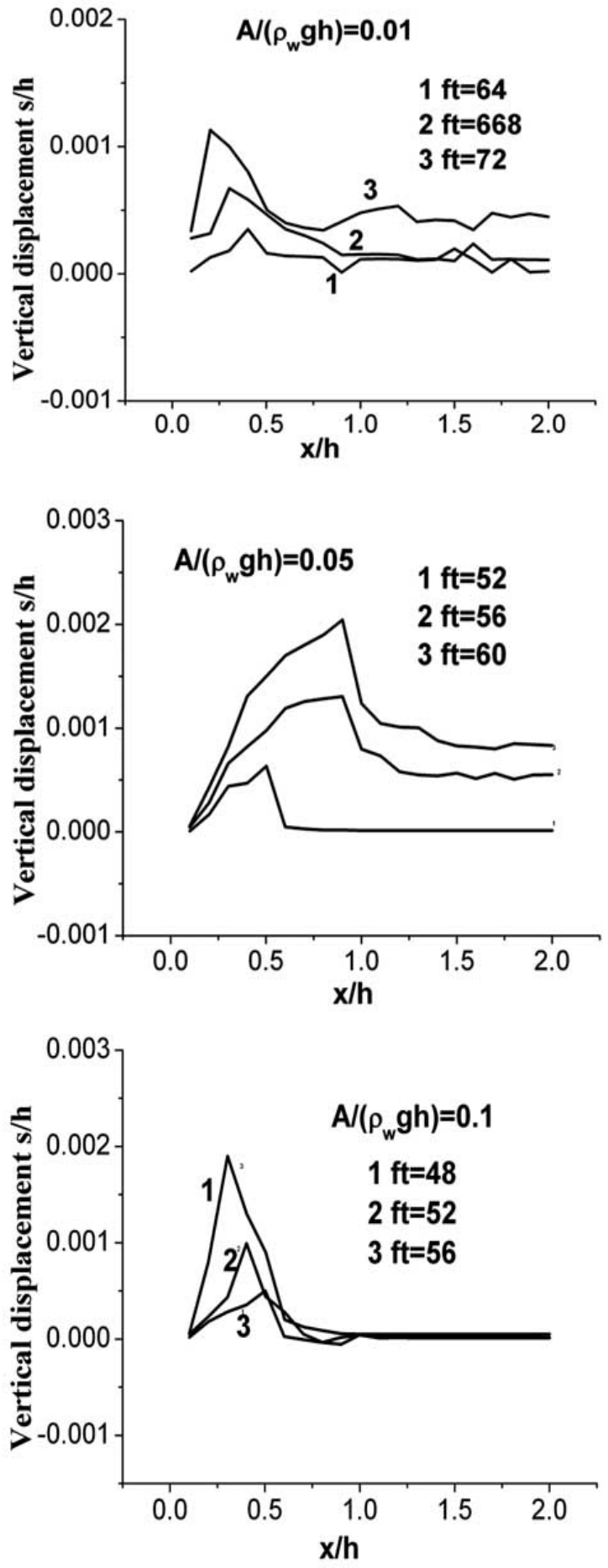

Fig. (6). The displacements on the surface of the sand layer versus loading amplitude.

Fig. (7) shows the results of the deformation on the surface development under different frequency conditions. It is shown that the deformation development becomes larger with the increase of loading frequency. The deformation becomes lager and larger with time. The point which has the biggest deformation moves gradually far away from the loading end. 

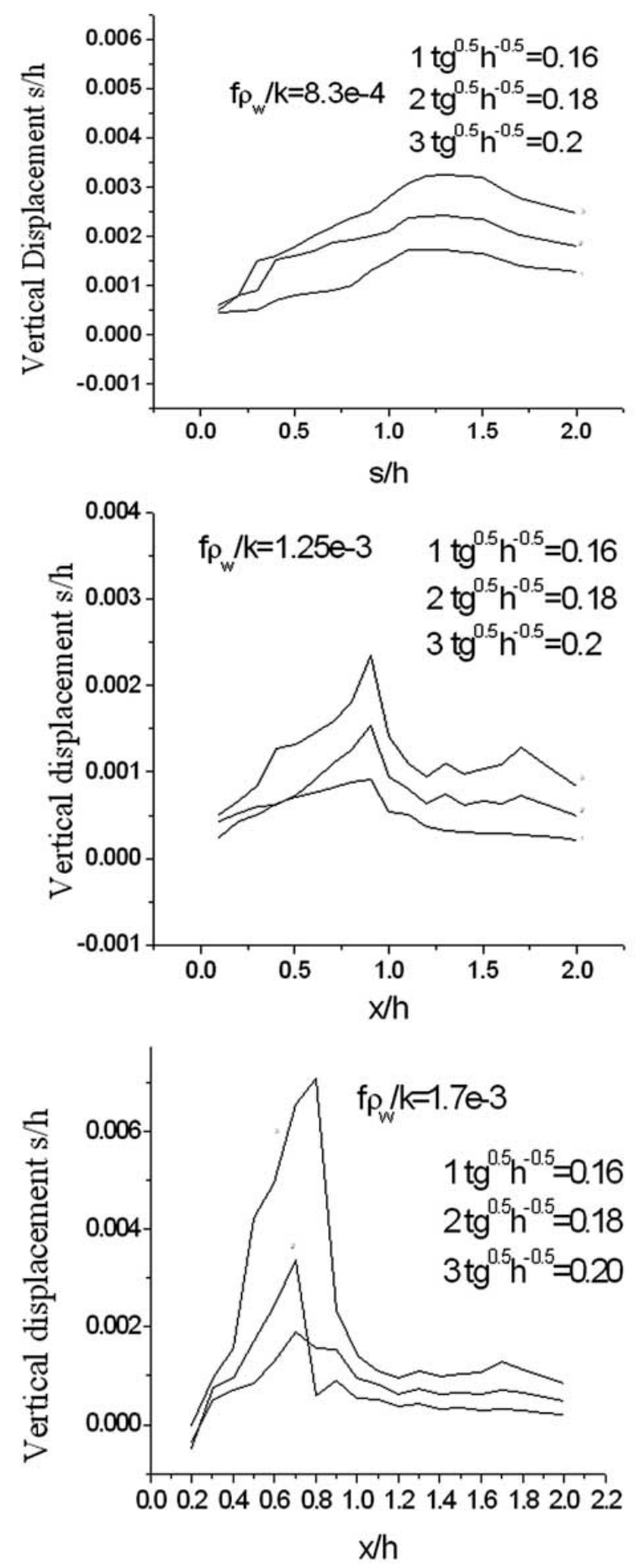

Fig. (7). The development of deformation versus load frequency.

\section{THE DEVELOPMENT OF THE PORE PRESSURE}

Fig. (8) shows the development of the pore pressure changing with time at the point of $h / 6$ below the sand surface. It is shown that under the vibration loading, the pore pressure in the saturated sand increases gradually and the strength of sand layer decreases gradually. At last, liquefaction occurs. It is agreement with the experiment results [18].
The deformation becomes smaller when the modulus of sand layer is smaller, the increase velocity of the pore pressure is faster. That means, the duration developing to liquefaction is shorter.
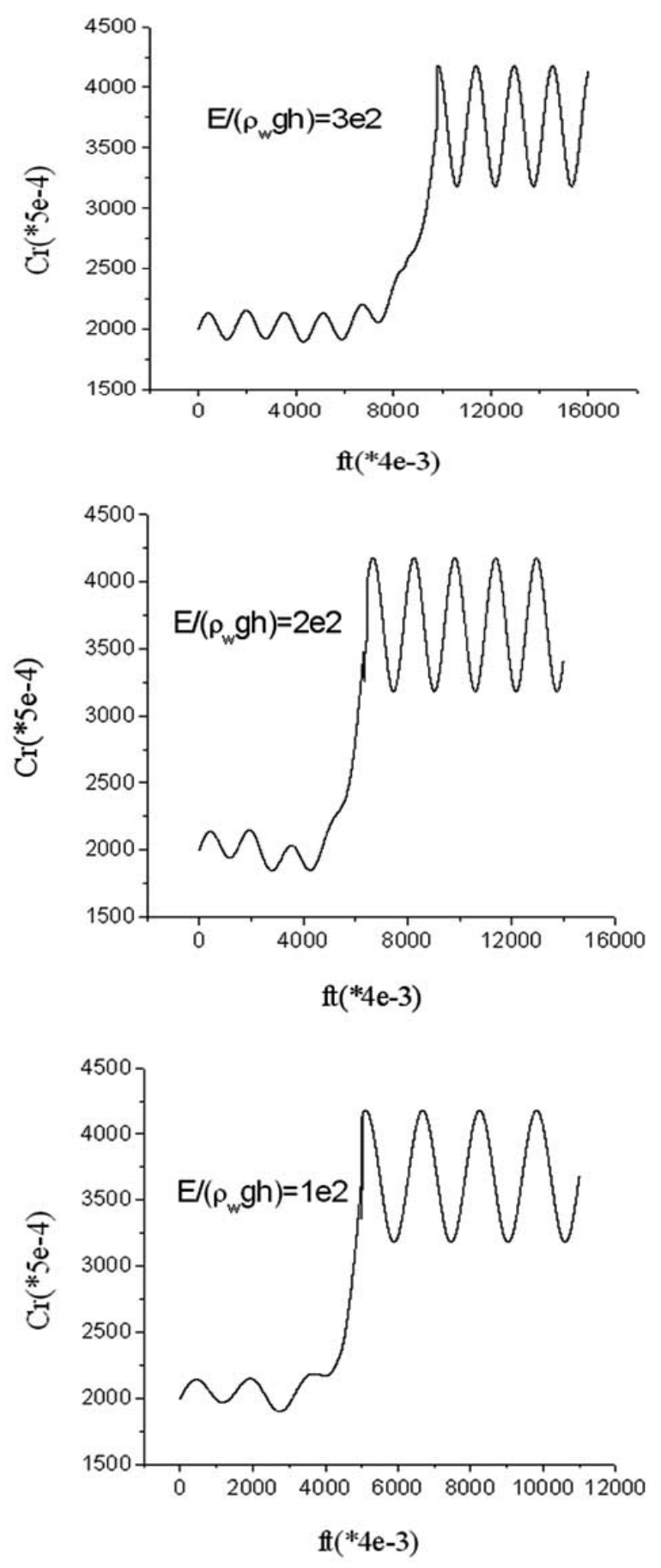

Fig. (8). The pore pressure versus time $\left(C r=\frac{p}{\rho_{w} g h}\right)$.

\section{CONCLUSIONS}

Under the vibrating loading on one side of the saturated sand, liquefaction occurs first near the loading end and then 
develops faraway. The deformation becomes up-heave near the loading end and degrades faraway gradually.

1. The liquefaction and the deformation develop fast with the increase of the loading amplitude and the frequency and the decrease of the modulus.

2. The liquefaction may occur under vibration loading on the side from the foundation side to a finite distance. It needs to be considered in the design of platform.

\section{ACKNOWLEDGEMENTS}

This program is supported by the fund of Chinese Ocean Oil Co. and Chinese Academy of Sciences"_KJCX2-SWL03-01"(40025103) and National Natural Science Fund (No. 10772182).

\section{REFERENCES}

[1] E. C. Clukey, M. J. Morrison, J. Garnier and J. F. Corte, "The response of suction caissons in: normally consolidated clays to cyclic TLP load conditions", In: Proc. Offshore Technol. Conf., Houston, OTC 7796, 1995, pp. 909-918.

[2] W. Dyme and G. T. Housby, "Drained behavior of suction caisson on very dense sand," In: Proc. Offshore Technol. Conf., Houston, OTC10994, 1998, pp. 765-782.

[3] T. L. Tjelta, J. Hermstad and E. Andenaes, "The skirt piled gullfaks c platform installation," In: Proc. Offshore Technol. Conf., Houston, OTC6473, 1990, pp. 453-462.

[4] A. Bye, C. Erbrich, B. Rognlien, and T.I. Tjelta, "Geotechnical design of bucket foundation," In: Proc. Offshore Technol. Conf., Houston, OTC7793, 1995, pp. 869-883.

[5] G. T. Housby and B. W. Byrne, "Suction caisson foundations for offshore wind turbines and anemometer masts", Wind Eng., vol. 24, No.4, pp. 249-255, 2000.
[6]

B. W. Byrne, G. T. Housby, P.M. Fish and C.M. Martin, "Suction caisson foundations for offshore wind turbines", Wind Eng., vol. 26, No. 3, pp. 145-155, 2002.

[7] K.H. Andersen and H.P. Jostad, "Foundation design of skirted foundations and anchors in clay," In: Proc. Offshore Technol. Conf., Houston, Texas, OTC 10824, 1999, pp. 1-10.

[8] T. I. Tjelta, T. R. Guttormsen and J. Hermstad, "Large-scale penetration test at a deepwater site," In: Proc. Offshore Technol. Conf., Houston, OTC 5103, 1986, pp. 201-212.

[9] D. Senpere, and G.A. Auvergne, "Suction anchor piles-a proven alternative to driving or drilling," In: Proc. Offshore Technol. Conf., Houston, OTC4206, 1982, pp. 483-493.

[10] X.B. Lu, Y.R. Wu and B.T. Jiao, "Centrifugal experimental study of suction bucket foundations under dynamic loading," Acta Mech. Sin., vol. 23, pp. 689-698, 2007.

[11] W.A. Marr and J.T. Christian, "Permanent displacements due to cyclic wave loading", J. Geotech. Eng. ASCE, Vol. 107, no. GT8, pp. 1129-1149, 1981.

[12] H.G. B. Allersma, F.J.A. Plenevaux, and J.F.P.C.M.E. Wintgens, "Simulation of suction pile installation in sand in a geocentrifuge," In: Proc. $7^{\text {th }}$ Int. Offshore and Polar Eng. Conf., vol. 1, 1997, pp. 761-765.

[13] M. A. Biot, "Theory of propagation of elastic waves in: a fluidsaturated porous solid", J. Acoust. Soc. Am., vol. 28, pp. 168-191, 1956.

[14] M.A. Biot, "Mechanics of deformation and acoustic propagation in: porous media", J. Appl. Phys., vol. 33, pp. 1482-1498, 1962.

[15] E. Green and P. M. Naghdi, "A dynamical theory of interacting continua", Int. J. Eng. Sci., vol. 3, pp. 231-241, 1965.

[16] O. C. Zienkiewicz, C. T. Changa and P. Bettess, "Drained, undrained, consolidating and dynamic behaviour assumptions in: sands limits of validity”, Geotechnique, vol. 30, pp. 385-395, 1980.

[17] X.B. Lu, "The analysis on liquefaction of saturated sand under vertical vibration loading", Dissertation for $\mathrm{Ph}$. D., Institute of $\mathrm{Me}$ chanics, Chinese Academy of Sciences, Beijing, 1999.

[18] X. B. Lu, J. H. Zhang, S. Y. Wang, G.L. Sun and Z.M. Shi, "Experimental study of the pore pressure and deformation of suction bucket foundations under horizontal dynamic loading," Chin. Ocean Eng. vol. 19, No. 4, pp. 671-680, 2005.

(C) Lu et al.; Licensee Bentham Open.

This is an open access article licensed under the terms of the Creative Commons Attribution Non-Commercial License (http://creativecommons.org/licenses/by-nc/3.0/) which permits unrestricted, non-commercial use, distribution and reproduction in any medium, provided the work is properly cited. 